\title{
Rhombencephalitis by Listeria monocytogenes: Onset of Symptoms Two Days After Perianal Injections
}

Serious infections with Listeria monocytogenes are known to occur in newborns, in immunosuppressed persons and in tumor patients (1-3). We are reporting a fatal course of encephalitis with $L$. monocytogenes in an otherwise healthy man.

\section{Case Report}

A 45-year-old high school teacher received perianal injections from a proctologist because of hemorrhoids. Except for mild hypertension (50 mg atenolol daily) and a private stress situation (widower, three young children), he was in an otherwise good physical condition. $36 \mathrm{~h}$ after receiving the perianal injections he noticed shivering. In the following six days nausea, vomiting, headaches, fever, and hemiataxia developed progressively. The patient was admitted to hospital. The cerebrospinal fluid revealed a pleocytosis of $10 \mathrm{cells} / \mathrm{mm}^{3}$, Pandy's reaction was negative and no bacterial growth developed. Two blood cultures were negative and a computed tomography of the brain was inconclusive. Since a focal bacterial encephalitis in the area of pons and medulla was considered as one possibility for this neurological desorder, antibiotic treatment with chloramphenicol (6 g daily) was started. Nevertheless, the condition gradually worsened within one week, and the patient had to undergo controlled ventilation. The computed tomography at that time demonstrated a localized hypodense area involving pons, medulla and part of the cerebellum. Thus, it appeared that this rhombencephalic syndrome with tetraplegia and coma (stage IV) had resulted from infarction following thrombosis in the A. basilaris. Therefore, antibiotic therapy was discontinued. Two days Iater, the patient died from circulatory failure. Pre-finally obtained blood cultures revealed $L$. monocytogenes after death. The post-mortem examination disclosed a dense infiltration of pons, medulla and cerebellum with $L$. monocytogenes without other pathological findings elsewhere in the brain.

\section{Discussion}

This case report illustrates that isolated hypodense areas (e.g. of the brain stem) detected by computed tomogra- phy should be judged cautiously with regard to etiology, even if the particular area corresponds to the blood flow distribution of one artery (e.g. A. basilaris). More importantly, the question arises as to whether manipulation of the proctologist may have triggered a transient bacteremia with $L$. monocytogenes. Since it is known that L. monocytogenes can occur in human feces of otherwise healthy carriers $(4,5)$, perianal injections could present a potential risk of introducing these bacteria into the blood. In the case reported, this may have been the first step in the development of a rhombencephalitis by $L$. monocytogenes.

F. W. Hirsch, H. Drexler, T. Meinertz, F. Daschner

\section{Literature}

1. Iwarson, S., Larsson, S.: Outcome of Listeria monocytogenes infection in compromised and non-compromised adults. Infection 7 (1979) $54-56$.

2. Seeliger, H. P. R., Emmerling, P., Emmerling, H.: Zur Verbreitung der Listeriose in Deutschland. Dtsch. Med. Wochenschr. 93 (1968) 2037-2043.

3. Barza, M.: Listeriosis and milk. N. Engl. J. Med. 312 (1985) 438-440.

4. Bojsen-Møller, J., Jesser, O.: Occurrence of Listeria monocytogenes in human feces: Epidemiological and pathogenic aspects. Proc. III Int. Symp. on Listeriosis, Bilthoven 1966, pp. 415-423.

5. Kampelmacher, E. H., Maas, D. E., van Noorle-Jansen, L. M.: Occurrence of Listeria monocytogenes in feces of pregnant women with and without direct animal contact. Zentralbl. Bakteriol. 234 (1976) 238-242.

Priv.-Doz. Dr, med. F. W. Hirsch, Dr. med. H. Drexler, Prof. Dr. med. T. Meinertz, Prof. Dr. med. F. Daschner, Medizinische Universitätsklinik, Hugstetter Straße 55, D-7800 Freiburg. 